\title{
In Vitro Ototoxicity of Aminoglycosides and Platin Derivatives. A Semi-automatic Assay for Sensory Hair Cell Damage in Explanted Rat Organ of Corti
}

\author{
B. MALGRANGE ${ }^{1, *}$, P. P. LEFEBVRE ${ }^{1,2}$, T. R. van de WATER ${ }^{3}$, \\ C. BONNET ${ }^{1}$, F. MONVILLE ${ }^{1}$, J.-M. RIGO ${ }^{1}$, H. STAECKER ${ }^{1,3}$ and \\ G. MOONEN $^{1}$ \\ ${ }^{1}$ Department of Human Physiology and Pathophysiology, University of Liège, 17 place delcour, \\ B-4020, Liège, ${ }^{2}$ Department Otorhinolaryngology and Audiophonology, University of Liège, B-4000 \\ Liège, Belgium and ${ }^{3}$ Departments of Otolaryngology and Neuroscience, Albert Einstein College of \\ Medicine, Bronx, New York, USA
}

(Accepted 29 March 1998)

\begin{abstract}
The ototoxic damage that drugs such as neomycin, kanamycin, colistin, cisplatin, transplatin and carboplatin cause on outer and inner hair cells in postnatal day 3 rat cochlear explants was investigated. Phalloidin-fluorescein conjugate-stained stereocilia bundles of sensory hair cells were quantified by video image analysis as a measurement of ototoxic effect. The video image quantification system established dose-response curves for ototoxic drugs (e.g. calculation of an $\mathrm{IC}_{50}$ ) and allowed comparisons between several ototoxins from the same family. This methodology provided the means to assess the efficacy of otoprotectant agents in preventing ototoxicity. Poly-l-aspartate $\left(10^{-5} \mathrm{M}\right)$ and poly-1-glutamate $\left(10^{-5} \mathrm{M}\right)$ protected auditory hair cells from neomycin $\left(10^{-3} \mathrm{M}\right)$ toxicity while reduced glutathione $\left(10^{-3} \mathrm{M}\right)$ provided protection against cisplatin $\left(10^{-4} \mathrm{M}\right)$-induced hair cell damage. (C) 1998 Published by Elsevier Science Ltd. All rights reserved
\end{abstract}

Keywords: cochlea; aminoglycosides; cisplatin; ototoxicity; otoprotection.

Abbreviations: $\quad$ DMEM $=$ Dulbecco's modified Eagle's medium; $\quad$ GSH $=$ reduced glutathione; $\mathrm{IHC}=$ inner hair cells; OHC $=$ outer hair cells; PBS = phosphate buffered saline.

\section{INTRODUCTION}

Hearing loss and impairment of balance are classical side-effects of important classes of therapeutic agents, for example, antibiotics of the aminoglycoside family and anticancer agents such as platin derivatives (Chiodo and Alberti, 1994; Harpur, 1981). The primary targets of these drugs in the inner ear are the sensory hair cells of hearing and balance, but the molecular mechanisms that lead to hair cell death remain poorly understood.

Assessment of toxicity is a major concern in the pharmaceutical field, and the development of in vitro systems that can rapidly screen for toxicity could help to avoid long, expensive in vivo studies. Therefore, the first goal of the present study is to establish an in vitro semi-automatic system for the quantification of ototoxic damage that would allow

*Author for correspondence. rapid screening of the auditory hair cells toxicity of new drugs or of new derivatives of known ototoxic drugs, in order to select new compounds and derivatives that have the best therapeutic effect/toxicity ratios. As ototoxic compounds may have different biochemical mechanisms of toxicity, we surmized that the number of hair cells would be a good common parameter for the evaluation of toxicity. Pattern recognition of the inner and outer hair cell stereocilia allows for the counting of these two types of auditory hair cells. Hair cell stereocilia and cuticular plates are known to be rich in F-actin filaments that can be labelled with phalloidinFITC, thereby allowing visualization of the normal pattern of stereocilia bundles of both the inner and outer hair cells, since there is no specific marker for hair cells.

One approach to minimize the functional consequences of ototoxic side-effects is to prevent ototoxic damage by co-administration of substances 
that decrease or suppress the drug's ototoxicity without interfering with their therapeutic effect.

In order to validate our in vitro model, we have quantified the effects of several well-known ototoxic drugs: (1) antibacterial aminoglycosides (neomycin, kanamycin); (2) polypeptide antibiotics (colistin); and (3) antineoplastic drugs (cisplatin, carboplatin, transplatin) (Gandara et al., 1991; Koegel, 1985; Wersäll, 1995). In a second part, we have investigated the applicability of our system as a tool to screen for otoprotective agents. We have chosen the most ototoxic aminoglycoside and antineoplastic drugs, respectively neomycin and cisplatin, in order to evaluate the efficacy of potential protective agents in the in vitro model.

Besides hair cells toxicity, aminoglycosides antibiotics are known to be highly nephrotoxic agents by inducing death of kidney proximal tubule epithelial cells (Morin et al., 1980; Tulkens, 1989). Several studies in rats have shown that poly-1-aspartic acid, a polyanionic agent, prevents or suppresses the nephrotoxic effects of aminoglycosides without decreasing their antibiotic effectiveness (Williams and Hottendorf, 1985; Williams et al., 1986). We have therefore chosen to determine whether the reported prevention of nephrotoxicity could be effective in protecting the hair cells of the inner ear from ototoxic damage.

Reduced glutathione (GSH) has been shown to prevent the toxic peripheral neuropathy induced by cisplatin, both in experimental animals (Cavaletti et al., 1994; Hamers et al., 1993; Tredici et al., 1994) and in humans (Cascinu et al., 1995). Therefore we also have assayed for an effect of GSH on cisplatin ototoxicity in vitro.

\section{MATERIALS AND METHODS}

Culture of explants containing the organ of Corti and the spiral ganglion

3-Day-old Wistar rats were killed by cervical transection, their bullae exposed and the temporal bones removed and transferred into a glass petri dish containing Dulbecco's phosphate buffered saline (PBS). Using watchmaker forceps, cochleae were dissected with the aid of a stereomicroscope. After opening the bony capsule, the cochlear duct was removed as a single piece together with its band of spiral neurons. Explants were cultured in Dulbecco's modified Eagle's medium (DMEM) supplemented with glucose (final concentration $6 \mathrm{~g}$ / litre), the $\mathrm{N}_{1}$ cocktail (Bottenstein and Sato, 1979) and $10 \%$ of foetal bovine serum (DMEM-FBS) into wells of a 96-well microculture plate (Nunc). Each explant of Corti's organ was cultured in suspension in individual wells containing $100 \mu \mathrm{l}$ medium. The cultures were kept at $37^{\circ} \mathrm{C}$ in a humidified atmosphere of $95 \%$ air and $5 \% \mathrm{CO}_{2}$. For toxicity screening, the medium was removed after an initial period of $24 \mathrm{hr}$ of culture and, after two rinses with DMEM to remove the serum, replaced with $100 \mu \mathrm{l}$ DMEM containing an appropriate concentration of the test drug for $48 \mathrm{hr}$, while control explants received only DMEM. For the screening of otoprotective substances, the explants were first cultured in the presence of the potential otoprotective agent for an initial 24-hr period. The medium was then removed, and replaced by medium containing both the ototoxic drug and the potential otoprotectant for an additional $48 \mathrm{hr}$ of culture. At the end of each experiment, the explant specimens were fixed and stained for F-actin.

\section{Tested substances}

The toxicity of well known cochleotoxic drugs such as neomycin, kanamycin, colistin, cisplatin, carboplatin and transplatin were tested at concentrations ranging from $10^{-3}$ to $10^{-6} \mathrm{M}$ (five concentrations at least per tested drug). Chloramphenicol, a non-ototoxic antibiotic was used as a control. The potential otoprotective agents tested were poly-1aspartate (mol. wt 5000-15,000), poly-l-glutamate (mol. wt 2000-15,000) and poly-l-ornithine (mol. wt 5000-15,000) for neomycin and GSH for cisplatin.

\section{Histochemical determination of F-actin}

Explants were fixed with paraformaldehyde 4\% at room temperature for $30 \mathrm{~min}$ and then incubated in PBS-Triton X100 1\% for $15 \mathrm{~min}$. The fixed-permeabilized cultures were subsequently exposed to phalloidin-FITC (1:60) for $45 \mathrm{~min}$ at room temperature. After $45 \mathrm{~min}$, the explants were washed twice in PBS and mounted on glass slides with nonfading PBS/glycerol. In order to avoid variations due to base to apex gradients of susceptibility to ototoxic compounds (Harpur, 1987), only midportions of the phalloidin FITC-stained explants corresponding to the midturn were selected. Immunostained stereocilia bundles were observed using a Bio-Rad MRC-1000 confocal system coupled to a Zeiss Axiovert microscope.

\section{Quantification of ototoxicity}

The number of hair cells was determined by video imaging using an IBAS-2000 image analysis system (Kontron). Confocal files were transfered to the image analysis software. The first step increased the image contrast by first superimposing it 200fold and, secondly, "normalized" it by scaling the actual grey levels linearly into the full dynamic range of the image memory. In a second step, a threshold level of grey shading was established in order to detect all of the hair cell stereocilia bundles. A threshold low enough to detect all stereocilia bundles must be used, otherwise part of them will be lost during data acquisition and subsequent analysis. After this step, each object that was under threshold was in black and every object that was above threshold was in white thus allowing visual- 
Table 1. Number of inner and outer hair cells in untreated organ of Corti explants as determined by video image analysis of phalloidinFITC stained stereocilia bundles

\begin{tabular}{|c|c|c|c|c|c|}
\hline Field & Length of explant $(\mu \mathrm{m})$ & No. of IHC (mm) & No. of $\mathrm{OHC}(\mathrm{mm})$ & $\operatorname{IHC}(\%)$ & $\mathrm{OHC}(\%)$ \\
\hline 1 & 229.3 & 100 & 331 & 23 & 77 \\
\hline 2 & 225.9 & 93 & 328 & 22 & 78 \\
\hline 3 & 210.1 & 119 & 357 & 25 & 75 \\
\hline \multirow[t]{2}{*}{4} & 256.3 & 94 & 332 & 22 & 78 \\
\hline & & 101 & 337 & 23 & 77 \\
\hline $\begin{array}{l}\text { mean } \\
\text { SD }\end{array}$ & & \pm 12 & \pm 13 & & \\
\hline
\end{tabular}

Each field represents the quantification of auditory hair cells in the middle part of an individual explant, $\mathrm{n}=4$.

ization of a digitized microscopic image. The background of cell debris or particulate matter was eliminated from the image by grey-level erosion. Every object was assigned its own object label for necessary identification before counting. Computerrecognized immunostained stereocilia bundles were projected in colour over the original digitized microscopic image in order to compare the processed data with the original image. The length of the preparation was measured and the results were expressed in number of hair cell stereocilia bundles per millimetre of Corti's organ. For each condition, four adjacent fields selected from the midportion of each explant were analysed blindly for three explants representing each condition (total number of fields $=12$ ). This program also allows differential counting of outer $(\mathrm{OHC})$ and inner hair cells (IHC) by manual separation in the stored digitized image of the three rows of outer hair cells from the row of inner hair cells. Statistical analysis was undertaken using a standard Student's $t$-test.

\section{Products and reagents}

DMEM and FCS were obtained from Gibco (Gent, Belgium). In all experiments, DMEM was supplemented with the $\mathrm{N}_{1}$ cocktail (bovine insulin $5 \mu \mathrm{g} / \mathrm{ml}$, progesterone $10^{-8} \mathrm{M}$, putrescine $100 \mu \mathrm{M}$, transferrin $100 \mu \mathrm{g} / \mathrm{ml}$ and selenium $3 \times 10^{-8} \mathrm{M}$ ) and the glucose concentration was increased to $6 \mathrm{~g} /$ litre. All reagents used were of analytical grade and were purchased from Sigma.

\section{RESULTS}

Image analysis of organ of Corti explants after phalloidin-FITC staining

It is well established that the mammalian organ of Corti is equipped with three rows of OHCs and a single row of IHCs and provided that each row has the same number of cells, quantitative data obtained from stereocilia bundles counts of normal organ of Corti explants should be composed of $75 \%$ OHCs and $25 \%$ IHCs. This is shown in Table 1 , in which the number of OHCs and IHCs is expressed per unit length of Corti's organ for four different control samples and, as predicted, OHCs are about three times more numerous per unit length than IHCs, thus validating our procedure of image analysis.
Quantification of hair cell toxicity of aminoglycosides and platin derivatives

Plate 1 illustrates morphological aspects of phalloidin-FITC-stained mid-portions of organ of Corti explants in six different conditions: neomycin $\left(10^{-3} \mathrm{M}\right.$, Plate $\left.1 \mathrm{~A}\right)$, kanamycin $\left(5 \times 10^{-2} \mathrm{M}\right.$, Plate 1B), colistin $\left(10^{-4} \mathrm{M}\right.$, Plate $\left.1 \mathrm{C}\right)$, cisplatin $\left(10^{-3} \mathrm{M}\right.$, Plate 1D) and carboplatin $\left(10^{-4} \mathrm{M}\right.$, Plate 1E). Chloramphenicol $\left(10^{-3} \mathrm{M}\right)$, a non-ototoxic antibiotic, was used as negative control (Plate 1F). As can be see in photomicrographs A,B,C, D and E of Plate 1, it is difficult to identify $\mathrm{OHC}$ and $\mathrm{IHC}$ in the treated cultures because of the disorganizing effect that these agents have on stereocilia bundle integrity. We have therefore established dose-response curves by considering only the total number of auditory hair cells per unit length. These curves have allowed the calculation of an $\mathrm{IC}_{50}$ which corresponds to the concentration of the test drug at which $50 \%$ of the hair cells are no longer detectable by phalloidin-FITC staining (Table 2). In the analysis of ototoxic effects, it has been observed that equimolar concentrations of kanamycin are less toxic than neomycin, which fits with clinical data that show a greater ototoxicity for neomycin in clinical subjects (Harpur, 1989). Similarly, equimolar concentrations of carboplatin have been found to be less toxic to auditory hair cells when compared with cisplatin. These observations also agree with clinical observations (Saito et al., 1989; Schweitzer et al., 1986; Taudy et al., 1992).

Protective effect of poly-l-glutamic and poly-l-aspartic acid against neomycin toxicity

Poly-1-ornithine (a polycationic agent) was used as a control for the investigation of the protective

Table 2. $\mathrm{IC}_{50} *$ of various pharmacologicals agents on auditory hair cells in vitro

\begin{tabular}{lr}
\hline & $\mathrm{IC}_{50}(\mathrm{M})$ \\
\hline Colistin & $0.2 \times 10^{-3}$ \\
Neomycin & $0.6 \times 10^{-3}$ \\
Kanamycin & $4.0 \times 10^{-3}$ \\
Cisplatin & $0.33 \times 10^{-4}$ \\
Carboplatin & $1.0 \times 10^{-4}$ \\
Transplatin & $1.3 \times 10^{-4}$ \\
\hline
\end{tabular}

*The $\mathrm{IC}_{50}$ represents the drug concentration at which there is a $50 \%$ decrease in the total number of hair cells as measured by video image analysis. 
Table 3. Protective effect of poly-1-aspartate and poly-l-glutamate on neomycin toxicity quantified by video image analysis*

\begin{tabular}{lcccc}
\hline $\begin{array}{l}\text { Neomycin } \\
(\mathrm{mM})\end{array}$ & Alone & $\begin{array}{c}\text { poly-1-aspartate } \\
\left(10^{-5} \mathrm{M}, 72 \mathrm{hr}\right)\end{array}$ & $\begin{array}{c}\text { poly-1-glutamate } \\
\left(10^{-5} \mathrm{M}, 72 \mathrm{hr}\right)\end{array}$ & $\begin{array}{c}+ \text { poly-l-ornithine } \\
\left(10^{-7} \mathrm{M}, 72 \mathrm{hr}\right)\end{array}$ \\
\hline 0.2 & $92 \pm 7^{* *}$ & $109 \pm 6$ & $106 \pm 12$ & $98 \pm 10$ \\
0.4 & $83 \pm 7$ & $100 \pm 12 \dagger$ & $\mathrm{N} . \mathrm{D}$. & $\mathrm{N} . \mathrm{D}$. \\
0.6 & $52 \pm 5$ & $106 \pm 10 \dagger$ & $103 \pm 10 \dagger$ & $48 \pm 8$ \\
1 & $1 \pm 2$ & $99 \pm 12 \dagger$ & $107 \pm 15 \dagger$ & $2 \pm 2$ \\
\hline
\end{tabular}

N.D. = non determined

*Protection explants are pretreated with protective compound for $24 \mathrm{hr}$ before exposure to neomycin.

**Results are expressed in percentage of hair cells as compared to control cultures (mean $\pm \mathrm{SD}, \mathrm{n}=12$ ).

$\uparrow$ Statistically significant compared with cultures exposed to neomycin alone.

effect of poly-l-aspartate and poly-l-glutamate (polyanionic agents). The protective effect on hair cell survival measured by quantification of hair cells bundles of both poly-l-aspartate and poly-l-glutamate is presented in Plate 2 and Table 3. A control explant is illustrated in Plate $2 \mathrm{~A}$ and poly-1-aspartate and poly-l-glutamate exposed cultures had a similar appearance. The protective agents have no effect on hair cells morphology. No protection against the ototoxic effect of neomycin was obtained using poly-l-ornithine. Both polyanionic drugs, poly-l-aspartate and poly-l-glutamate, protect against neomycin-induced hair cell toxicity at the highest tested concentration, namely $10^{-3} \mathrm{M}$.

\section{Protective effect of GSH against cisplatin toxicity}

The number of cisplatin-damaged hair cells is significantly reduced in the presence of GSH (Plate 3), thus demonstrating a protective effect of GSH on cisplatin-induced hair cell damage. GSH alone has no effect on hair cell morphology or number (Plate 3A). Quantitative analysis of the protective effect of GSH is presented in Table 4, and shows that $10^{-3} \mathrm{M}$ GSH had a significant protective effect up to a $10^{-4} \mathrm{M}$ concentration of cisplatin but fails to protect at the $10^{-3} \mathrm{M}$ level of drug concentration. No protection was obtained using GSH $\left(10^{-3} \mathrm{M}\right)$ and neomycin $\left(10^{-3}-10^{-4} \mathrm{M}\right)$, showing that the mechanism of GSH otoprotection appears to be selective.

\section{DISCUSSION}

Auditory hair cells have been well established as the primary targets of various ototoxic agents, particularly with aminoglycosides antibiotics and anti-

Table 4. Protective effect of GSH against cisplatin-induced damage of auditory hair cells as quantified by video image analysis*

\begin{tabular}{lcc}
\hline Cisplatin (M) & Untreated & $\pm \mathrm{GSH}\left(10^{-3} \mathrm{M}\right)$ \\
\hline $10^{-6}$ & $101 \pm 7$ & $103 \pm 6 * *$ \\
$10^{-5}$ & $68 \pm 12$ & $100 \pm 9.4 \dagger$ \\
$3 \times 10^{-5}$ & $49.9 \pm 21$ & $94.9 \pm 23.2 \dagger$ \\
$10^{-4}$ & $28 \pm 11$ & $81.6 \pm 19.2 \dagger$ \\
$10^{-3}$ & $9 \pm 10$ & $10 \pm 12$ \\
\hline
\end{tabular}

*P3 rat organ of Corti explants: $24 \mathrm{hr}$ untreated; $48 \mathrm{hr}$ cisplatin or cisplatin + GSH.

**Results are expressed in percentage of hair cells compared with control (mean $\pm \mathrm{SD}, \mathrm{n}=12)$.

$\uparrow$ Statistically significant. cancer platin derivatives (Kroese and Van den Bercken, 1980; Taudy et al., 1992). Their death in the organ of Corti results in sensory deafness which, in humans, is irreversible. Loss of hearing threshold due to ototoxic poisoning of auditory hair cells in birds has been shown to be transient. Indeed, in avians, the damaged inner ear has been shown to self-repair through the process of hair cell regeneration (Ryals and Rubel, 1988). As the induction of hair cell regeneration appears to be far away from clinical application in humans and since some ototoxic drugs still have to be administrated to the patient for life-threatening diseases, an otoprotection strategy should be developed in order to prevent damage to the inner ear. Such an approach has already been proposed, and the use of various molecules, such as radioprotectant (Pierson and Moller, 1981), thyroid hormone (Hangfu et al., 1992) or high calcium concentrations (Takada and Schacht, 1982), has been shown to be effective in protecting the inner ear from specific insults that result in hair cell degeneration. However, to achieve the goal of protecting hair cells from injury, we need to develop a reliable and fast model to screen potential ototoxic and otoprotective drugs. For this purpose, in vitro models appear to be suitable (Kotecha and Richardson, 1994; Richardson and Russell, 1991) and are currently used in our laboratory (Lefebvre et al., 1989, 1990, 1993). The semi-automatic method of quantification using a video image analysis system presented in this paper allows rapid and objective quantification of the number of hair cells $/ \mathrm{mm}$ of Corti's organ in organotypic explants. Using this technique, we have established dose-response curves and calculated $\mathrm{IC}_{50} \mathrm{~s}$, which allow comparisons between different drugs (see Table 2). This screening for ototoxic effects can potentially be extended to any existing or newly synthesized molecules with different mechanisms of ototoxicity. However, it is important to emphasize the limitations of our model, which are: (1) our method does not in the strict sense quantify hair cell death, but rather hair cell injury as demonstrated after phalloidin-FITC staining; (2) this in vitro model cannot explain or study the toxicologic molecular mechanism of the drugs; and (3) this in vitro system cannot reproduce the in vivo accumulation of ototoxic drugs, especially aminoglycosides, in the perilymph or the endolymph 

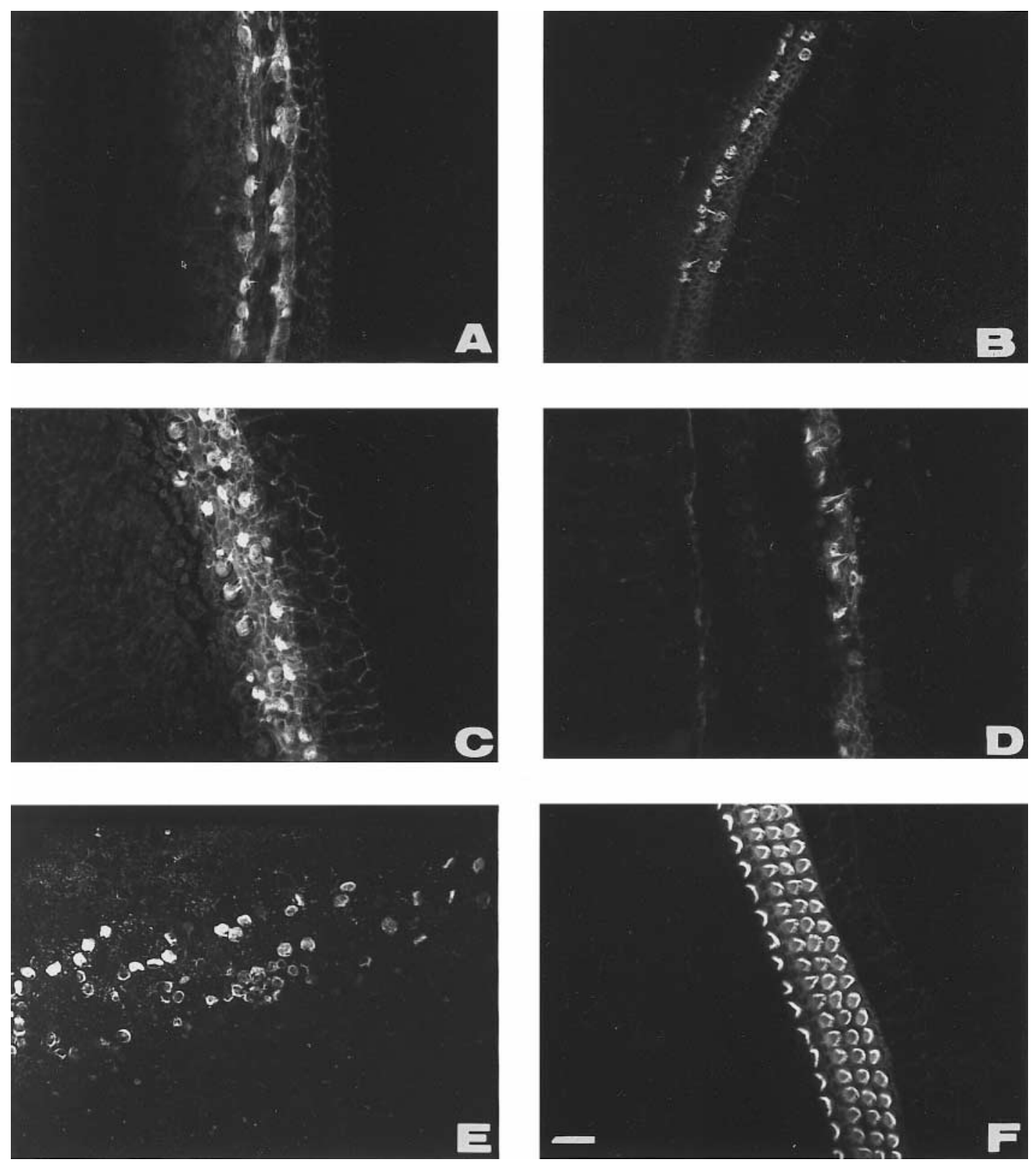

Plate 1. Morphology of hair cell stereocilia bundles of organ of Corti explants, after $72 \mathrm{hr}$ in vitro. Treatments groups (initial $24 \mathrm{hr}$ in vitro then $48 \mathrm{hr}$ exposure to drugs); (A) neomycin $10^{-3} \mathrm{M}$; (B) kanamycin $5 \times 10^{-2} \mathrm{M}$; (C) colistin $10^{-4} \mathrm{M}$; (D) cisplatin $10^{-3} \mathrm{M}$; (E) carboplatin $10^{-4} \mathrm{M}$; and (F) chloramphenicol $10^{-3}$ M. Phalloidin-FITC staining, Bar $=20 \mu \mathrm{m}$.

Plates 2 and 3 [overleaf]

Plate 2. Otoprotection against neomycin ototoxicity in organ of Corti explants, after $72 \mathrm{hr}$ in vitro. Morphology of hair cell stereocilia bundles in: (A) and (C) neomycin alone for $48 \mathrm{hr}(0.6 \mathrm{~mm}$ and $1 \mathrm{~mm}$, respectively); (B) and (D) neomycin (0.6 mM and $1 \mathrm{~mm}, 48 \mathrm{hr}$, respectively) and poly-1-aspartic acid $\left(10^{-5}\right.$ M, $\left.72 \mathrm{hr}\right)$. Phalloidin-FITC staining, Bar $=20 \mu \mathrm{m}$.

Plate 3. Otoprotection against cisplatin ototoxicity in organ of Corti explants, after $72 \mathrm{hr}$ in vitro. Morphology of hair cell stereocilia bundles in: (A) glutathione $\left(10^{-3} \mathrm{M} ; 72 \mathrm{hr}\right.$ ) alone; (B) cisplatin alone $\left(10^{-4} \mathrm{M}\right)$; $(\mathrm{C})$ cisplatin $\left(10^{-4} \mathrm{M} ; 48 \mathrm{hr}\right)$ and glutathione $\left(10^{-3} \mathrm{M} ; 72 \mathrm{hr}\right)$. Phalloidin-FITC staining, $\operatorname{Bar}=20 \mu \mathrm{m}$. 

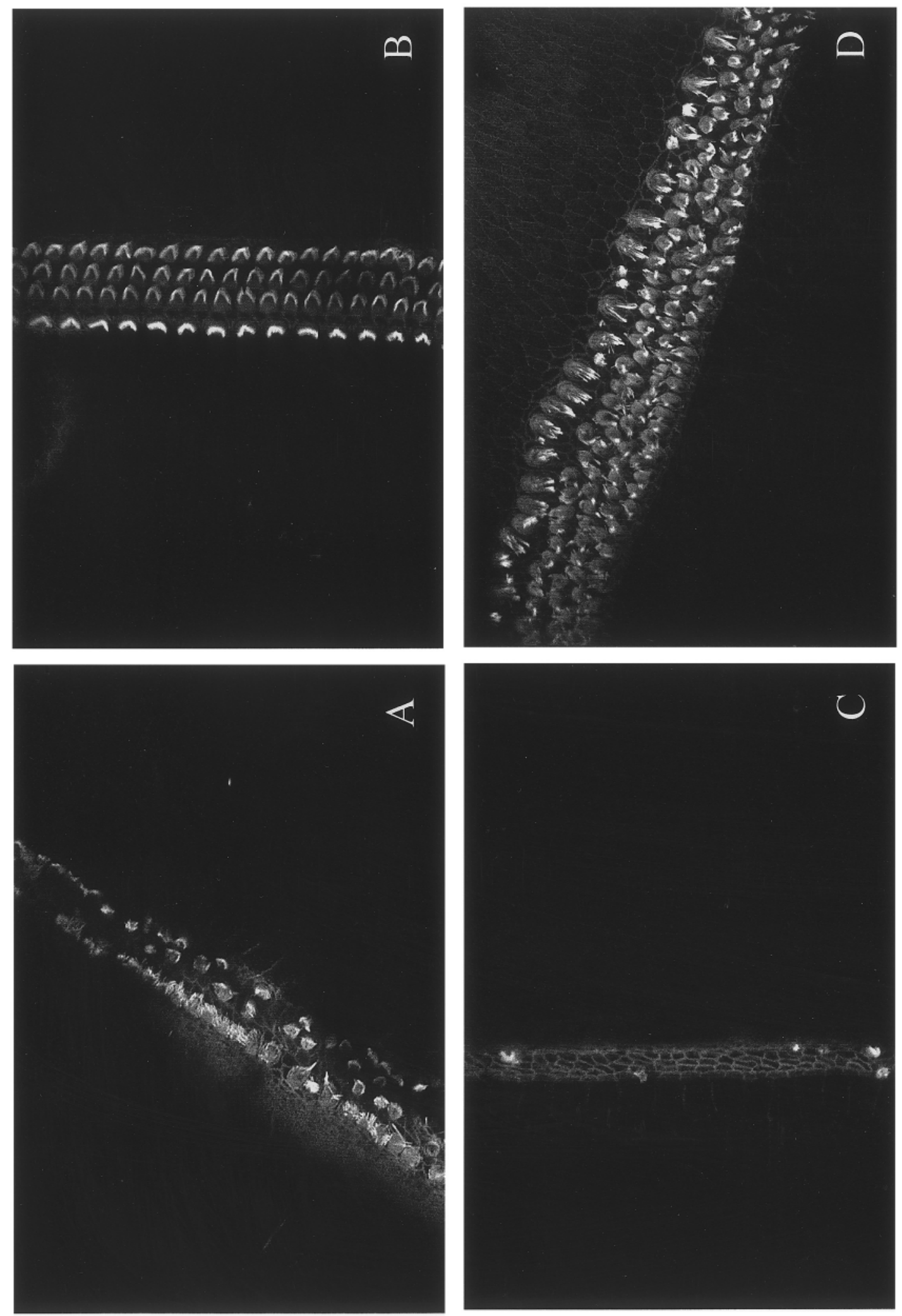

0
$\frac{0}{2}$
$\frac{0}{2}$ 

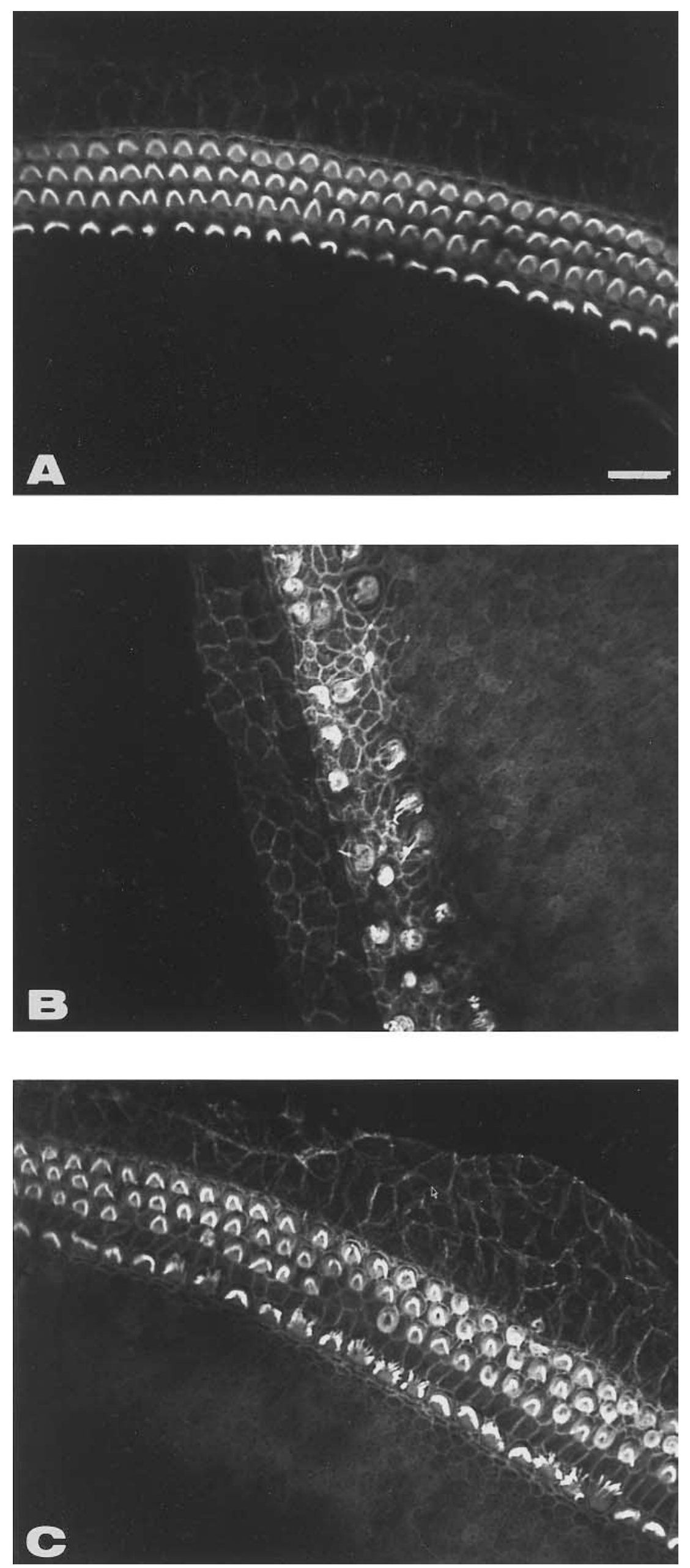

Plate 3. 

(Tran Ba Huy et al., 1981). This could explain why high concentrations had to be used in order to observe an ototoxic effect.

Perhaps the most interesting application of this quantification system is its ability to screen for substances that can be used to prevent the ototoxic side-effect of various drugs for which no alternative exists in terms of therapeutic strategies. In this study, we have selected as potential otoprotective agents, substances which could be used in the clinic and which have been found to protect other target organs from toxicity, namely polyanions and GSH.

Indeed, systemic administration of polyaminoacids, including poly-l-aspartic and poly-l-glutamic acid, has been reported to provide protection against the development of aminoglycoside-induced nephrotoxicity in the rat, as assessed by histopathology scoring, and to prevent functional and biochemical lesions (Ramsammy et al., 1988). One of the objectives of this study was to extend and test in the inner ear the observation that poly-l-aspartate protects the rat kidney against the development of aminoglycosides nephrotoxicity. As can be seen in Plate 2 and Table 3, poly-1-aspartate and poly-l-glutamate to a large extent protect auditory hair cells against neomycin-induced ototoxic damage in our in vitro model. Polyanions, such as poly-l-aspartate or polyl-glutamate, may protect against aminoglycoside ototoxicity by forming electrostatic complexes with these drugs and inhibiting their interaction with critical intracellular or extracellular target, as has been shown for the protection of their nephrotoxicity (Ramsammy et al., 1990). Another hypothesis could be the direct interaction of the polyanion with the plasma membrane instead of the aminoglycosides, which may constitute one of the first steps of their toxic mechanism of action (Schacht, 1986; Williams et al., 1987). That type of protection is also specific for aminoglycoside antibiotics and explains why we have not found any protection against cisplatin ototoxicity (data not shown).

GSH is reported to diminish cisplatin-induced neurotoxicity, and patients treated with cisplatin in combination with GSH (doses ranging from 1.5 to $3 \mathrm{~g} / \mathrm{m}^{2}$ ) exhibit a less severe neuropathic syndrome with no negative interference of its anticancer activity in these patients (Cavaletti et al., 1996; Colombo et al., 1995; Di Re et al., 1993). Experimental studies performed on rats have shown that GSH provides protection against the cisplatininduced slowing of sensory nerve conduction velocity without interfering with the antitumour efficacy of this drug (Hamers et al., 1993). Our in vitro data demonstrate that GSH also protects hair cells from cisplatin-induced injury, although not for the highest cisplatin concentration. However, histopathological studies of deafness resulting from cisplatin poisoning demonstrate that not only are hair cells damaged, but that auditory neurons are also injured (Schweitzer et al., 1986). Therefore, similar investigations have to be undertaken to look for a potential protective effect of GSH on auditory neurons. This assumption seems reasonable since our preliminary data suggest that a protective effect of GSH occurs in vitro on adult rat dorsal root ganglion neurons, and since in vivo treatment with GSH decreases the platinum concentration in DRG neurons (Cavaletti et al., 1992). The otoprotective mechanism has to be elucidated, since the mechanism of cisplatin ototoxicity is still unknown. Cisplatin ototoxicity may be a result of accumulation of reactive oxygen species (Rybak et al., 1995); in that case, GSH could protect by a detoxification mechanism. A possible explanation is based on the chemical structure of cisplatin: GSH would form complexes with cisplatin thereby preventing the formation of similar complexes between cisplatin and macromolecules of the inner ear responsible of cisplatin ototoxicity, and such a protective mechanism would explain the absence of a GSH protective effect for aminoglycoside ototoxicity.

In conclusion, our results show that the potential protective molecules tested - polyanions and GSHprotect respectively against aminoglycosides and cisplatin derivatives ototoxicity. To what extent these data obtained in vitro on post-natal organ of Corti material will be confirmed in vivo and lead to preservation of hearing remains to be shown. The in vitro screening model presented in this report allows, for the quantification of ototoxicity, a comparison of relative toxicity of various drugs from the same family and the testing of otoprotective agents. This system provides a powerful tool for the design and evaluation of otoprotective strategies. Indeed, systemic administration of poly-l-aspartate was recently demonstrated to prevent the shift in the auditory brain stem response threshold that occurs with gentamicin treatment (Hulka et al., 1993).

Acknowledgements - This work was supported by grants from the National Fund for Scientific Research of Belgium to BM, GM and PPL, the Concerted Action of the Government of the French Community of Belgium to BM and GM and the Queen Elisabeth Medical Foundation of Belgium to GM, National Institute for Deafness and other Communication Disorders (DC00088) and the Shulsky Fund for Hearing Research of the Montefiore Medical Center to TRV. We thank P. Ernst for her technical assistance.

\section{REFERENCES}

Bottenstein J. E. and Sato G. (1979) Growth of rat neuroblastoma cell line in serum-free supplemented medium. Proceedings of the National Academy of Sciences of the U.S.A. 76, 514-517.

Cascinu S., Cordella L., Del Ferro E., Fronzoni M. and Catalano G. (1995) Neuroprotective effect of reduced glutathione on cisplatin-based chemotherapy in advanced gastric cancer: a randomized double-blind placebo-controlled trial. Journal of Clinical Oncology 13, 26-32.

Cavaletti G., Cascinu S., Venturino P., Tedeschi M. and Tredici G. (1996) Neuroprotectant drugs in cisplatin neurotoxicity. Anticancer Research 16, 3149-3160. 
Cavaletti G., Minoia C., Schieppati M. and Tredici G. (1994) Protective effects of glutathione on cisplatin neurotoxicity in rats. International Journal of Radiation, Oncology, Biology and Physics 29, 771-776.

Cavaletti G., Tredici G., Pizzini G., Marmiroli P., Fabbrica D. and Mincia R. (1992) Morphologic, morphometric and toxicologic evaluations of the effect of cisplatin alone or in combination with glutathione on the rat nervous system. Clinical Neuropharmacology 11, 169-169.

Chiodo A. A. and Alberti P. W. (1994) Experimental, clinical and preventive aspects of ototoxicity. (Review). European Archives of Oto-Rhino-Laryngology 251, 375392.

Colombo N., Bini S., Miceli D., Bogliun G., Marzorati G., Cavaletti G., Parmigiani F., Venturino P., Tedeschi M., Frattola L., Buratti C. and Mangioni C. (1995) Weekly cisplatin $+/-$ glutathione in relapsed ovarian carcinoma. International Journal of Gynecological Cancer 5, 81-86.

Di Re F., Bohm S., Oriana S., Spatti G. B., Pirovano C., Tedeschi M. and Zunino F. (1993) High-dose cisplatin and cyclophosphamide with glutathione in the treatment of advanced ovarian cancer. Annals of Oncology 4, 5561.

Gandara D. R., Perez E. A., Weibe V. and De Gregorio M. W. (1991) Cisplatin chemoprotection and rescue: pharmacologic modulation of toxicity. (Review). Seminars in Oncology 18, 49-55.

Hamers F. P. T., Brakkee J. H., Cavalletti E., Tedeschi M., Marmonti L., Pezzoni G., Neijt J. P. and Gispen W. H. (1993) Reduced glutathione protects against cisplatin-induced neurotoxicity in rats. Cancer Research 53, 544-549.

Hangfu M., Zhao J. and Din D. (1992) The prophylactic effect of thyroxin on kanamycin ototoxicity in guinea pigs. Hearing Research 61, 132-136.

Harpur E. S. (1981) Ototoxicity. In In Vitro Methods in Toxicology. Edited by C. K. Atterwill and C. E. Steele, pp. 37-58. Cambridge University Press, London.

Harpur E. S. (1987) The inner ear. In Target Organ Toxicity. Edited by G. M. Cohen, pp. 125-142. CRC Press, Boca Raton, FL.

Harpur E. S. (1989) Ototoxicity: morphological and functional correlations between experimental and clinical studies. In Perspectives in Basic and Applied Toxicology. Edited by B. Ballantyne, pp. 42-69. Wright, London.

Hulka G. F., Prazma J., Brownlee R. E., Pulver S. and Pillsbury H. C. (1993) Use of poly-l-aspartic acid to inhibit aminoglycoside cochlear ototoxicity. American Journal of Otology 14, 352-356.

Koegel L. (1985) Ototoxicity: a contemporary review of aminoglycosides, loop duretics, acetylsalicylic acid, quinine, erythromycin, and cisplatinum. American Journal of Otology 6, 190-199.

Kotecha B. and Richardson G. P. (1994) Ototoxicity in vitro: effects of neomycin, gentamicin, dihydrostreptomycin, amikacin, spectinomycin, neamine, spermine and poly-L-lysine. Hearing Research 73, 173-184.

Kroese A. B. A. and Van den Bercken J. (1980) Dual action of ototoxic antibiotics on sensory hair cells. Nature 283, 395-397.

Lefebvre P. P., Demanez S., Weber T. and Moonen G. (1989) Trophic and toxic effects on cultured hair cells and spiral ganglia neurons. Acta Otolaryngologica Belgica 43, 39-40.

Lefebvre P. P., Malgrange B., Staecker H., Moonen G. and Van De Water T. R. (1993) Retinoic acid stimulates regeneration of mammalian auditory hair cells after ototoxic damage in vitro. Science 260/5108, 692694.

Lefebvre P. P., Weber T., Rigo J-M., Delrée P., Leprince P. and Moonen G. (1990) Potassium-induced release of an endogenous toxic activity for outer hair cell and auditory neurons in the cochlea: a new pathophysiological mechanism in Ménière's disease? Hearing Research 47, 83-94.

Morin J. P., Viotte G., Vandewalle A., Van Hoof F., Tulkens P. and Fillastre J. P. (1980) Gentamicininduced nephrotoxicity: a cell biology approach. Kidney International 18, 583-590.

Pierson M. G. and Moller A. R. (1981) Prophylaxis of kanamycin-induced ototoxicity by a radioprotectant. Hearing Research 4, 79-87.

Ramsammy L., Josepovitz C., Lane B. and Kaloyanides J. (1990) Polyaspartic acid inhibits gentamicin-induced perturbations of phospholipid metabolism. American Journal of Physiology 259, C1141-C1149.

Ramsammy L., Josepovitz C., Lane B. P. and Kaloyanides G. J. (1988) Polyaspartic acid protects against gentamicin nephrotoxicity in the rat. Journal of Pharmacology and Experimental Therapeutics 1, 149153.

Richardson G. P. and Russell I. J. (1991) Cochlear cultures as a model for studying aminoglycoside induced ototoxicity. Hearing Research 53, 293-311.

Ryals B. M. and Rubel E. W. (1988) Hair cell regeneration after acoustic trauma in adult coturnix quail. Science 240, 1774-1776.

Rybak L. P., Ravi R. and Somani S. M. (1995) Mechanism of protection by diethyldithiocarbamate against cisplatin ototoxicity: antioxidant system. Fundamental and Applied Toxicology 26, 293-300.

Saito T., Saito H., Saito K., Wakui S., Manabe Y. and Tsuda G. (1989) Ototoxicity of carboplatin in guinea pigs. Auris Nasus Larynx 16, 13-21.

Schacht J. (1986) Molecular mechanisms of drug-induced hearing loss. Hearing Research 22, 297-304.

Schweitzer V. G., Rarey K. E., Dolan D. F. and Abrams G. (1986) Ototoxicity of cisplatin vs. platinum analogs CBDCA (JM-8) and CHIP (JM-9). Otolaryngology, Head and Neck Surgery 94, 458-470.

Takada A. and Schacht J. (1982) Calcium antagonism and reversibility of gentamicin-induced loss of cochlear microphonics in guinea pig. Hearing Research 8, 179186.

Taudy M., Syka J., Popelár J. and Ulehlová L. (1992) Carboplatin and cisplatin ototoxicity in guinea pigs. Audiology 31, 293-299.

Tran Ba Huy P., Manuel C., Meulemans A., Sterkers O. and Amiel C. (1981) Pharmacokinetics of gentamicin in perilymph and endolymph of the rat as determined by radioimmunoassay. Journal of Infectious Diseases 143, 476-486.

Tredici G., Cavaletti G., Petruccioli M. G., Fabbrica D., Tedeschi M. and Venturino P. (1994) Low-dose glutathione administration in the prevention of cisplatininduced peripheral neuropathy in rats. Neurotoxicology 15, 701-704.

Tulkens P. M. (1989) Nephrotoxicity of aminoglycoside antibiotics. Toxicology Letters 46, 107-123.

Wersäll J. (1995) Ototoxic antibiotics: a review. Acta Otolaryngology (Stockholm) 519, 26-29.

Williams P. D. and Hottendorf G. H. (1985) Inhibition of renal membrane binding and nephrotoxicity of gentamicin by polyasparagine and polyaspartic acid in the rat. Research Communications in Chemical Pathology and Pharmacology 47, 317-320.

Williams P. D., Hottendorf G. H. and Bennett D. B. (1986) Inhibition of renal membrane binding and nephrotoxicity of aminoglycosides. Journal of Pharmacology and Experimental Therapeutics 237, 919-925.

Williams S. E., Zenner H. P. and Schacht J. (1987) Three molecular steps of aminoglycoside ototoxicity demonstrated in outer hair cells. Hearing Research 30, 11-18. 